This is a self-archived version of an original article. This version may differ from the original in pagination and typographic details.

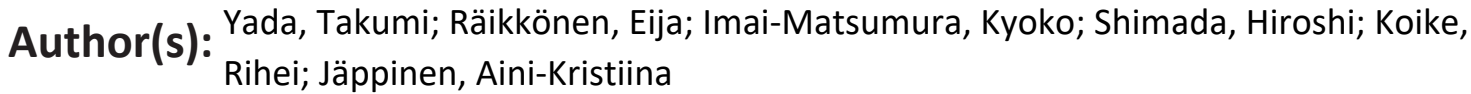

Title: Prosociality as a mediator between teacher collaboration and turnover intention

Year: 2020

Version: Accepted version (Final draft)

Copyright: @ 2019 EMERALD PUBLISHING LIMITED

Rights: In Copyright

Rights url: http://rightsstatements.org/page/InC/1.0/?language=en

Please cite the original version:

Yada, T., Räikkönen, E., Imai-Matsumura, K., Shimada, H., Koike, R., \& Jäppinen, A.-K. (2020). Prosociality as a mediator between teacher collaboration and turnover intention. International Journal of Educational Management, 34(3), 535-548. https://doi.org/10.1108/IJEM-10-20180309 


\section{Prosociality as a mediator between teacher collaboration and turnover intention}

Takumi Yada ${ }^{1}$, Eija Räikkönen ${ }^{1}$, Kyoko Imai-Matsumura ${ }^{2}$, Hiroshi Shimada ${ }^{2}$, Rihei Koike ${ }^{3}$, Aini-Kristiina Jäppinen ${ }^{1}$

${ }^{1}$ Faculty of Education and Psychology, University of Jyväskylä, Jyväskylä, Finland

${ }^{2}$ The Joint Graduate School in Science of School Education, Hyogo University of Teacher Education, Kato, Japan ${ }^{3}$ Himeji Municipal Shikama-chubu Junior High School, Himeji, Japan, and

\section{Introduction}

Recently, teacher collaboration has attracted the attention of researchers for its potential to improve educational organisational effectiveness (Goddard et al., 2007). Meanwhile, a high rate of teacher turnover is not only a problem for work force and resource planning but also an indicator of the poor quality of schools (Vagi et al., 2019; Smethem, 2007). Acting on the assumption that collaborative practices enhance teachers' commitment to teaching at their school, researchers have shown considerable interest in the relationships between collaborative practices in schools and their effect on turnover intention, as an indicator of organisational effectiveness (e.g. Kraft et al., 2016; Smith and Ingersoll, 2004). However, despite these findings (Guin, 2004; Simon and Johnson, 2015), little is known about the process by which those effects are realised.

Organisational researchers have indicated that prosociality, which involves people caring about creating a positive difference in other's lives, enhances individual and organisational effectiveness (Batson, 2012; Grant, 2007). Grant's (2007) elaborate theoretical framework suggests that relational job architecture - composed of interaction, cooperation and collaboration - enhances workers' motivation to make a prosocial difference through prosocial impact on the 
beneficiaries of their work, thereby leading to job persistence, which represents employee commitment to work. In educational organisations, teachers help and benefit others. While students are the end beneficiaries of collaborative educational endeavours, teacher colleagues also benefit from them (Tschannen-Moran, 2001; Victorino et al., 2018).

However, many educational researchers have not explicitly defined the term prosocial. They have studied prosocial elements by using other-oriented concepts, such as caring, empathy, organisational citizenship behaviour and servant leadership (e.g. Goroshit and Hen, 2016; Somech, 2016). This is because, first, being prosocial is a context-specific expression in public and service institutions and especially in educational organisations (Bright, 2008; Grant and Campbell, 2007). Second, educational organisations fundamentally require a relational job architecture, such as collaboration (Hallinger and Heck, 2010). Yet, although previous studies suggest that prosociality is relevant to collaboration (Hu and Liden, 2015; Tschannen-Moran, 2001; Victorino et al., 2018), teacher collaboration mitigates teacher turnover intention (Simon and Johnson, 2015), and prosociality eases teachers' stress (Eldor and Shoshani, 2016), little is known about prosociality itself and the potential role it plays in the linkage between teacher collaboration and their turnover intentions. Therefore, the purpose of this study is to investigate the mediating role of prosociality in the relationship between teacher collaboration and their turnover intention, with the help of the Job Impact Framework (Grant, 2007).

\section{Literature background}

\section{Collaboration in school as relational job architecture}

Studies indicate that collaboration in school has a considerable job impact on organisational members and offers plenty of opportunities to make a difference (e.g. Brouwer et al., 2012; 
Slater, 2005). This is because a successful collaboration requires synergistic, dynamical and shared performance of teachers and other co-workers in order to achieve collective goals (Jäppinen and Ciussi, 2016).

Teacher collaboration embodies relational job architecture in that it provides opportunities to benefit others (e.g. Eldor and Shoshani, 2016; Tschannen-Moran, 2001). Relational job architecture consists of job impact on beneficiaries and contact with beneficiaries in a relational structure (Grant, 2007). Regarding job impact, individuals become aware that their efforts can have a substantial impact on the beneficiaries when encountering a job opportunity that benefits others (Grant, 2007). For example, participative decision making at the school level is a form of collaboration (Bogler and Somech, 2005) that influences students and other educational staff. Through contact with beneficiaries, individuals learn about how their work affects these beneficiaries. For example, teachers' collaboration involves contacts with beneficiaries through creating time and spaces, and developing open-mindedness that facilitate discussions between colleagues, offering physical and human resources (Jäppinen et al. 2015; Hord and Sommers, 2008). Hence, collaboration in teaching jobs typically involves enriched relational architectures in which teachers have enormous impacts on others' lives.

\section{Prosocial impact}

Prosocial impact refers to the experience of recognising one's work as significant and purposeful because of its links to the welfare of others or the perception of making a positive difference in the lives of others (Grant, 2007). This is important for sense-making and well-being, as prosocial impact pertains to the meaning that people attach to their behaviours in the social world and the lens through which employees process, appraise and make sense of their experiences (Grant and Campbell, 2007). 
Teachers perceive that their work is meaningful and makes a difference (GuramatunhuMudiwa and Scherz, 2013; Shapira-Lishchinsky and Tsemach, 2014). Since teachers interact, help and collaborate with others in an educational organisation (Slater, 2005; Tschannen-Moran, 2001), teaching provides opportunities to benefit others and to influence their welfare. Therefore, teachers can perceive prosocial impact.

\section{The relationship between collaboration and prosocial impact}

Teachers engaged in collaborative efforts are likely to perceive prosocial impact because they feel valued when their contributions towards benefitting others are successful (Crowther et al., 2009; Guramatunhu-Mudiwa and Scherz, 2013). For example, helping colleagues by using their knowledge and expertise makes teachers feel that their work is meaningful (e.g. ShapiraLishchinsky and Rosenblatt, 2010). Thus, we expect that perceived prosocial impact increases when teachers recognise that they are collaborating for their beneficiaries (Shapira-Lishchinsky \& Tsemach, 2014).

Hypothesis 1 (H1 in Figure 1): Perception of collaboration in school will be positively related to perceived prosocial impact.

\section{Prosocial motivation}

Prosocial motivation is an allocentric psychological state or a desire to benefit others (Batson, 1987; Grant, 2007). If one is highly prosocially motivated, one's attention is oriented towards the thoughts, feelings, preferences and welfare of other people in the interest of benefitting their lives (Hu and Liden, 2015).

Educational leaders' and teachers' prosocial motivation has been mostly studied from the point of view of helping others. Prosocial motivation has been conceptualised as empathy (e.g. 
Goroshit and Hen, 2016), caring (e.g. Noddings, 2006) and servant leadership (e.g. Taylor et al., 2007), which are deeply related to educational organisational phenomena such as collaboration. Thus, other-oriented motivation is considered an essential component of effective schools (DiPaola and Tschannen-Moran, 2001).

Prosocial motivation may operate at three hierarchical levels: global, contextual, and situational (Grant and Berg, 2011). Regarding the global level, teachers' helping behaviours stem from other-oriented values and their willingness to go beyond the formal requirements of their positions such as caring and altruism (e.g. Cerit, 2009; Noddings, 2006). At the contextual level, teachers are expected to be passionate about educating students (Grant and Campbell, 2007) and collaborate with their colleagues and principals for the achievements of the students (Goddard et al., 2007; Hargreaves, 1994). As for the situational level, teachers may want to help their coworkers in particular relationships such as mentoring and induction (Ingersoll and Strong, 2011).

\section{The relationship between prosocial impact and prosocial motivation}

The perception of high prosocial impact promotes perceived prosocial motivation (e.g. Bellé, 2013; Sonnentag and Grant, 2012). Grant (2007, p. 403) explains this mechanism that perceived impact signifies the behaviour-outcome contingency that promotes motivation. When people perceive that their actions are benefitting others, they are motivated to engage in making a difference for others. On the other hand, when people feel their work does not have an impact, they tend not to aim for the outcome of making a prosocial difference, because they feel they have less opportunity to achieve this outcome (Grant, 2007). Therefore, in school settings, we believe that the perceived prosocial impact of benefiting others is likely to promote teachers' prosocial motivation. 
Hypothesis 2 (H2 in Figure 1): Perceived prosocial impact will be positively related to perceived prosocial motivation.

\section{Turnover intention}

Previous studies suggest that withdrawal behaviour of teachers result in decreased school effectiveness (Rosenblatt et al., 2010; Shapira-Lishchinsky, 2012). Turnover is a type of withdrawal behaviour, akin to behaviours such as lateness and absenteeism, observed when an employee's job performance deteriorates (Kaplan et al., 2009). Turnover intention is a conscious and deliberate contemplation to leave an organisation (Tett and Meyer, 1993), and it has been studied as a proxy for actual voluntary turnover (Lambert and Hogan, 2009). Even though the intention to turnover may not materialise in actual voluntary turnover, it is important to examine the turnover intention for improving our understanding of the psychological process of withdrawal of employees (Lachman and Diamant, 1987).

Teachers leave their jobs for a number of reasons. Ingersoll (2001) described teachers' turnover by using concepts of movers and leavers. Movers switch to teaching jobs in other schools, and leavers leave the teaching occupation for good. Teaching is recognised as a human service occupation with chronic exposure to emotionally intense work (Grant and Campbell, 2007). Sometimes, this exposure leads to interpersonal stress, which is a great risk for leaving the profession (Ingersoll, 2001).

\section{The relationship between prosocial motivation and turnover intention, and prosociality as a mediator}

Prosocial motivation is closely linked to turnover intention. According to the framework by Grant (2007), people who experience prosocial motivation are energised to work harder and 
longer. From a motivational perspective, when people's actions benefit others, they are likely to feel that they matter and experience a meaningfulness that energises them (Grant, 2007). Also empirical findings have shown that employees with high prosocial motivation do not leave their jobs as easily as employees with low prosocial motivation (Hu and Liden, 2015). Therefore, we hypothesise that high prosocial motivation reduces turnover intentions of teachers in schools (Grant, 2007).

Hypothesis 3 (H3 in Figure 1): Perceived prosocial motivation will be negatively related to turnover intention.

Previous studies suggest that teachers have less turnover intention in climates with great regard for interpersonal relationships and collective process (Shapira-Lishchinsky, 2009;

Shapira-Lishchinsky and Rosenblatt, 2009). In addition, existing research shows that collaborative structures or environments in schools may directly affect teacher turnover (Kraft et al., 2016; Simon and Johnson, 2015; Smith and Ingersoll, 2004). Therefore, we assume that prosocial impact and prosocial motivation partially mediate the relationship between perception of collaboration and turnover intention.

Hypothesis 4 (H4 in Figure 1): Prosocial impact and prosocial motivation will mediate the relationship between perception of collaboration in school and turnover intention. However, only partial mediation is expected as a direct negative association between collaboration and turnover intention may also emerge.

\section{Research aims}

This study examines how teachers' perception of collaboration, prosocial impact, prosocial motivation and turnover intention are related (Figure 1). It is motivated by the following research questions: (1) How is the perception of collaboration related to prosocial impact? (2) How is 
prosocial impact related to prosocial motivation? (3) How is prosocial motivation related to turnover intention? (4) Do prosocial impact and prosocial motivation partially mediate the relationship between perception of collaboration and turnover intention?

[Figure 1 near here]

\section{Method}

\section{Ethical considerations}

Our study followed the official Finnish guidelines on Responsible Conduct of Research and Procedures for Handling Allegations of Misconduct in Finland (Finnish Advisory Board on Research Integrity, 2012), which correspond to the ethical guidelines of Japanese research institutions (Science Council of Japan, 2013). Before the survey, we explained the purpose of the study to the participants and assured them of complete confidentiality and anonymity. Participation was voluntary.

\section{Participants and procedure}

This study was conducted in 2017 in Himeji city, located in western Japan. Teachers from elementary and junior high schools were invited to the study. In 2017, there were 29,276 school teachers in the selected locations (Himeji City Administration, 2017). A convenience sampling was used to select the participants. We first sought permission to administer the survey from the concerned authorities. Most of the contacted persons were known to us. After obtaining the permissions, one of the researchers visited each school in the prefecture and gave the principals a set of paper-and-pencil questionnaires along with self-addressed and stamped envelopes. 
The final sample consisted of 260 professional educators: 150 teachers from elementary schools (57.7\%) and 110 teachers from junior high schools (42.3\%). They held different positions: 233 teachers (89.6\%), 7 principals (2.7\%), 8 vice-principals (3.1\%) and 12 heads of department (4.6\%). Teachers included classroom teachers, subject teachers and special education teachers, with either full-time or part-time contracts. The mean age of the educators was 39.88 years $(\mathrm{SD}=11.51)$, the mean tenure was 15.09 years $(\mathrm{SD}=11.28)$ and $39.2 \%$ of the educators were male. Most (96.9\%) of the educators held more than a bachelor's degree. The sample composition is broadly representative of the teacher-population in the Japanese educational context (Ministry of Education Culture Sport Science and Technology Japan, 2016).

The questionnaire was originally developed in English, and translated into Japanese by the first author, who is fluent in both Japanese and English. Then, the translated instrument was checked by a native Japanese researcher studying education. Finally, a licensed guide interpreter, who had taught English in Japanese high schools proofread the final version of the instrument and made corrections.

\section{Instruments}

\section{Collaboration}

Collaboration was measured by four items, which were developed by one of the authors on the basis of previous research (Jäppinen and Ciussi 2016; Jäppinen et al. 2015). The items were preceded by the following leading sentence: 'When working together, I feel that...'. The items were: 'everyone's contribution is considered (CL1)', 'we create meaningful measures and practices (CL2)', 'we are able to change our individual opinions as new perspectives arise (CL3)', and 'it results in new ideas and alternative solutions (CL4)' $(\alpha=.76)$. For each item, 
educators were asked to mark a position that best described their opinion on a visual analogue scale ranging from 0 to 50 (Dillman et al., 2014).

\section{Prosocial impact}

Prosocial impact was measured with three items adapted from Grant (2008a): 'I am very conscious of the positive impact that my work has on others (PI1)', 'I am very aware of the ways in which my work is benefitting others (PI2)', and 'I feel that I can have a positive impact on others through my work (PI3)' ( $\alpha=.88$ ). The items were measured on a 7-point Likert-type scale anchored at 1 disagree strongly and at 7 agree strongly.

\section{Prosocial motivation}

Prosocial motivation was measured with four items adapted from Grant (2008b). Educators responded the question, 'Why are you motivated to do the work as a teacher?' by rating the following options: 'Because I care about benefitting others through my work (PM1)', 'Because I want to help others through my work (PM2)', 'Because I want to have a positive impact on others (PM3)', and 'Because it is important to me to do good for others through my work (PM4)' $(\alpha=.89)$. The response scale was a 7-point Likert-type scale anchored at 1 disagree strongly and 7 agree strongly.

\section{Turnover intention}

Turnover intention was measured with three items adapted from Camman et al. (1979): 'I will probably look for a new job in near future (TI1)', 'If I may choose again, I will choose to work for this school (TI2) (score reversed)' and 'I often think about quitting (TI3)' $(\alpha=.66)$. The items were measured on a 7-point Likert-type scale anchored at 1 disagree strongly and 7 agree 
strongly.

\section{Analysis}

The associations between collaboration, prosocial impact, prosocial motivation and turnover intention (Figure 1) were examined via Structural equation modelling (SEM) implemented in Mplus, 7.0 (Muthén and Muthén, 2012). The few missing values (covariance coverage 99.9$100.0 \%$ ) were assumed to be missing at random, and, since the data were not normally distributed, the robust maximum likelihood estimator (MLR) was used. The Full-InformationMaximum-Likelihood (FIML) procedure was used to account for the missing data. FIML uses all available data without imputing the missing values. To evaluate the goodness-of-fit of the

hypothesised SEM model, $\chi^{2}$ value, comparative fit index (CFI), Tucker Lewis index (TLI), standardised root-mean-square residual (SRMR) and root-mean-square error of approximation (RMSEA) were estimated (Hooper et al., 2008). A good model fit yields an insignificant $p$-value associated with a $\chi^{2}$ value. Values lower than .07 for RMSEA, greater than .95 for CFI, and lower than .08 for SRMR were considered to indicate a good fit (Hooper et al., 2008; Hu and Bentler, 1999; Kline, 2016).

The mediating effects of prosocial impact and prosocial motivation were examined by the bootstrapping approach, using Mplus, with 2,000 iterations to calculate bias- corrected 95\% confidence intervals (CI) to estimate indirect effects (Preacher and Hayes, 2004).

\section{Results}

The descriptive statistics for the observed variables and their correlations are shown in Table 1. [Table 1 near here] 
We examined the preliminary measurement model in which the relationships between collaboration and prosocial impact, prosocial impact and prosocial motivation, prosocial motivation and turnover intention, and collaboration and turnover intention were correlated using confirmatory factor analysis (CFA). This model exhibited a moderately poor fit to the data $\left(\chi^{2}(71)=152.56, p<.001, \mathrm{RMSEA}=.07, \mathrm{CFI}=.93, \mathrm{TLI}=.91, \mathrm{SRMR}=.06\right)$. Consequently, the model was modified according to the information given by the modification indices (MIs). The MIs revealed covariance between the errors of the items PM1 and PM2 for prosocial motivation $(\mathrm{MI}=21.47)$ and the errors of the items $\mathrm{TI} 1$ and $\mathrm{TI} 3$ for turnover intention $(\mathrm{MI}=$ 14.07). After adding them, the model showed satisfactory approximation with the data $\left(\chi^{2}(69)=\right.$ $122.08, p<.001, \mathrm{RMSEA}=.05, \mathrm{CFI}=.95, \mathrm{TLI}=.94, \mathrm{SRMR}=.05)$.

Next, we applied SEM to assess the hypothesised path model between collaboration, prosocial impact, prosocial motivation and turnover intention. This hypothesised model did not fit the data well $\left(\chi^{2}(72)=138.15, p<.001, \mathrm{RMSEA}=.06, \mathrm{CFI}=.94, \mathrm{TLI}=.93, \mathrm{SRMR}=.07\right)$. However, the MIs indicated that a path between collaboration and turnover intention $(\mathrm{MI}=$ 12.10) should be added. We modified the model accordingly. This model fit the data reasonably well $\left(\chi^{2}(70)=130.10, p<.001, \mathrm{RMSEA}=.06, \mathrm{CFI}=.95, \mathrm{TLI}=.93, \mathrm{SRMR}=.06\right)$. In this final model (Figure 2), stronger collaboration was related to higher prosocial impact, which, in turn, was associated with higher prosocial motivation, supporting Hypotheses 1 and 2. Finally, in support of Hypothesis 3, prosocial motivation was negatively related to turnover intention: the higher the prosocial motivation teachers had, the less they reported turnover intentions. [Figure 2 near here]

The mediating effects of collaboration on turnover intention $(\beta=-.09$, bias-corrected $95 \% \mathrm{CI}=[-.15,-.02]$, excluding zero) via prosocial impact and prosocial motivation were found 
to be statistically significant. Thus, in support of Hypothesis 4, prosocial impact and prosocial motivation partially mediated the relationship between collaboration and prosocial motivation.

\section{Discussion}

This study examined the potential mediating role of prosociality between collaboration and turnover intention based on the framework by Grant (2007) in an educational context. Our results confirmed this linkage. That is, teachers engaged in a collaborative job structure felt that the positive impact of their work influences the well-being of others, thereby leading to the willingness to help others more (Grant, 2007; Hallinger and Heck, 2010). Moreover, collaboration at the school level, which provides teachers with the opportunities to interact, limited their turnover intention through the experience and motivation to help others (Guin, 2004; Simon and Johnson, 2015).

As hypothesised (Grant, 2007), teachers experienced high prosocial impact when they made a positive difference in others' lives through collaboration. In a collaborative environment, teachers share responsibilities and learn together to achieve school goals, thereby helping and benefitting others (Jäppinen et al. 2015). Their frequent interaction and collective decisionmaking towards school goals generate the experience that they are working for others' benefit, which ultimately leads to the welfare of the students. Since teacher collaboration has a helpful connotation, teachers perceive collaboration as a relational job that generates prosocial impact.

Since Grant (2007) proposed a relationship between prosocial impact and prosocial motivation, few studies have investigated it. This study showed that the more prosocial impact the teachers perceive, the more prosocial motivation they have. One possible explanation is that the affective benefit of prosocial impact comes later (Sonnentag and Grant, 2012). For example, people may feel prosocial impact at the end of the school day but not immediately at the end of 
the work. Prosocial impact boosts activated positive emotions such as excitement and inspiration by encouraging people to reflect on work (Sonnentag and Grant, 2012). Additionally, it enhances deactivated positive emotions such as calm and relaxation by enabling people to feel more competent. Thus, teachers who have helped others in their school recollect their contributions or the appreciation they have received for their work. The positive feedback energises them to help others more.

Echoing the previous studies (e.g. Kraft et al., 2016; Simon and Johnson, 2015; Smith and Ingersoll, 2004), we found a direct negative relationship between collaboration and turnover intention. This suggests that the association between collaboration and turnover intention was not fully mediated by prosociality; in fact, prosociality only partially explained why strong collaboration was linked to fewer intentions to leave the job. For example, a cooperative and supportive work environment is effective in preventing an organisation from losing its members (Hu and Liden, 2015). Support from colleagues is especially important for teachers' well-being (Smith and Ingersoll, 2004). It may also be that collaboration is an active process that requires engagement to achieve shared goals (Hu and Liden, 2015). This in turn may enhance the perceptions of a group's ability to achieve collective goals such as collective efficacy (Bandura, 1997). Such shared competency has been found to alleviate turnover intention (e.g. You and Conley, 2015).

Previously, prosociality has mostly been examined in relation to short-term tasks (Grant, 2008b). Our study shed light on the effects of prosociality from a new point of view: turnover intention or employees thoughts about quitting their long-term employment. This is an important contribution for two reasons. First, the use of long-term, instead of short-term, employment is more appropriate when considering the outcome of practical organisational activities. Second, 
actual turnover may not always be an outcome of prosociality in practical situations because many teachers modify their turnover intention for other reasons, such as difficult financial situations or re-employment issues, before actually quitting their jobs.

Our results support the findings of previous studies that have shown that other-oriented motivation makes people more tolerant in their jobs (e.g. Hu and Liden, 2015). For example, people who are concerned about others are likely to be resilient, which plays an important role in enhancing the ability to manage stress (Kinman and Grant, 2011). Thus, prosocially motivated teachers may be resilient and tolerant in their jobs because they want to help others more. It could also be that a teacher's core goals and objectives are defined in terms of helping others (Grant and Campbell, 2007). When one's personal value is congruent with the organisational value, the person show a long-term commitment to the organisation (e.g. Moynihan and Pandey, 2008). Since teachers hold values geared towards helping others, they may feel that they are working in accordance with their own values, which leads to less turnover intention when they are prosocially motivated.

\section{Limitations and future research}

Our cross-sectional data limits the potential for causal inferences. Although our analysis is based on Grant's (2007) theoretical framework, and our results support it, it is possible that reverse associations also exist. For example, it has been shown that collective prosocial motivation leads to employee cooperation (Hu and Liden, 2015). Therefore, a cross-lagged longitudinal design should be employed in the future to shed more light on the issue.

We used self-reported data. Therefore, we cannot rule out the possibility of a common source bias (i.e. participants used a cognitive schema to generalise their evaluations) (Podsakoff 
et al., 2010). Future research should use various data sources including, for example, data on collaboration evaluated by outside persons.

Our results offer several promising directions for future research. We did not discuss or examine prosocial motivation in relation to autonomy in self-regulation (Ryan and Deci, 2000). Teaching as an occupation requires emotional investments for others (Chang, 2009). If teachers are forced to have prosocial value, they may perceive their job negatively, and it may affect outcomes such as well-being. Therefore, the relationships between prosocial motivation and its potential outcomes should be examined in relation to other aspects of motivation.

Furthermore, prosocial orientation may differ across persons and positions. It has been shown that prosocial behaviour such as organisational citizenship behaviour can include different orientations, for example, towards individual, towards colleagues and towards the organisation (Somech, 2016). Thus, the orientation of prosocial motivation may have several possible competing levels, such as towards students, colleagues, and towards the school as an organisation.

\section{Practical implications and conclusion}

Our results draw attention to the importance of creating a job structure to generate the experience of benefitting others. Educational leaders should provide teachers with more opportunities to experience prosocial impact. For example, receiving positive feedback from colleagues boosts teachers' prosocial impact. Prosocial impact can also be enhanced when leaders' messages assure that teachers that their work has meaningful consequences for other people (Grant and Hofmann, 2011).

An educational organisation can use our findings to reduce teachers' turnover by encouraging a collaborative environment and prosocial motivation. For example, task 
interdependence is key to enhancing the relationship between prosocial motivation and employees' turnover (Hu and Liden, 2015). Thus, to facilitate interactions and communications, educational managements should carefully coordinate task-sharing activities among the school staff.

Educational scholars have often acknowledged the importance of other-oriented values in educational organisations (Cerit, 2009; DiPaola and Tschannen-Moran, 2001). However, few studies have explored what kind of environment cultivates these values and what kinds of behavioural outcomes they may generate. In line with the Job Impact Framework (Grant, 2007), this study demonstrated that teachers are motivated to help others in a collaborative environment that allows them to experience the process of benefitting others, thereby mitigating their intention to leave.

\section{References}

Bandura, A. (1997), Self-Efficacy: The Exercise of Control, Freeman, New York, NY.

Batson, C.D. (1987), "Prosocial motivation: Is it ever truly altruistic?", Advances in Experimental Social Psychology, Vol. 20, pp. 65-122.

Batson, C.D. (2012), “A history of prosocial behavior research", in Kruglanski, A.W. and Stroebe, W. (Eds.), Handbook of the History of Social Psychology, Psychology Press, New York, NY, pp. 243-264.

Bellé, N. (2013), "Leading to make a difference: A field experiment on the performance effects of transformational leadership, perceived social impact, and public service motivation", Journal of Public Administration Research and Theory, Vol. 24 No. 1, pp. 109-136.

Bogler, R. and Somech, A. (2005), "Organizational citizenship behavior in school: How does it relate to participation in decision making?", Journal of Educational Administration, Vol. 43 No. 5, pp. 420-438. 
Bright, L. (2008), "Does public service motivation really make a difference on the job satisfaction and turnover intentions of public employees?", The American Review of Public Administration, Vol. 38 No. 2, pp. 149-166.

Brouwer, P., Brekelmans, M., Nieuwenhuis, L. and Simons, R. (2012), “Community development in the school workplace", International Journal of Educational Management, Vol. 26 No. 4, pp. 403-418.

Camman, C., Fichman, M., Jenkins, D. and Klesh, J. (1979), “The Michigan Organizational Assessment questionnaire. Unpublished manuscript", University of Michigan, Ann Arbor.

Cerit, Y. (2009), “The effects of servant leadership behaviours of school principals on teachers' job satisfaction", Educational Management Administration \& Leadership, Vol. 37 No. 5, pp. $600-623$.

Chang, M. (2009), “An appraisal perspective of teacher burnout: Examining the emotional work of teachers", Educational Psychology Review, Vol. 21 No. 3, pp. 193-218.

Crowther, F., Ferguson, M. and Hann, L. (2009), Developing Teacher Leaders: How Teacher Leadership Enhances School Success, Corwin Press, Thousand Oaks, CA.

Dillman, D.A., Smyth, J.D. and Christian, L.M. (2014), Internet, Phone, Mail, and Mixed-Mode Surveys: The Tailored Design Method, John Wiley \& Sons, Hoboken, New Jersey.

DiPaola, M.F. and Tschannen-Moran, M. (2001), “Organizational citizenship behavior in schools and its relationship to school climate", Journal of School Leadership, Vol. 11 No. 5, pp. $424-447$.

Eldor, L. and Shoshani, A. (2016), "Caring relationships in school staff: Exploring the link between compassion and teacher work engagement", Teaching and Teacher Education, Vol. 59, pp. 126-136.

Finnish Advisory Board on Research Integrity. (2012), "Responsible conduct of research and procedures for handling allegations of misconduct in Finland", available at: http://www.tenk.fi/sites/tenk.fi/files/HTK_ohje_2012.pdf (accessed 3 November 2017). 
Goddard, Y.L., Goddard, R.D. and Tschannen-Moran, M. (2007), “A Theoretical and empirical investigation of teacher collaboration for school improvement and student achievement in public elementary schools", Teachers College Record, Vol. 109 No. 4, pp. 877-896.

Goroshit, M. and Hen, M. (2016), “Teachers' empathy: can it be predicted by self-efficacy?”, Teachers and Teaching: Theory and Practice, Routledge, Vol. 22 No. 7, pp. 805-818.

Grant, A.M. (2007), "Relational job design and the motivation to make a prosocial difference", Academy of Management Review, Vol. 32 No. 2, pp. 393-417.

Grant, A.M. (2008a), “The significance of task significance: Job performance effects, relational mechanisms, and boundary conditions", Journal of Applied Psychology, Vol. 93 No. 1, pp. $108-124$.

Grant, A.M. (2008b), "Does Intrinsic Motivation Fuel the Prosocial Fire? Motivational Synergy in Predicting Persistence, Performance, and Productivity", Journal of Applied Psychology, Vol. 93 No. 1, pp. 48-58.

Grant, A.M. and Berg, J.M. (2011), "Prosocial motivation at work: When, why, and how making a difference makes a difference", in Cameron, K. and Spreitzer, G. (Eds.), The Oxford Handbook of Positive Organizational Scholarship, Oxford University Press, Oxford, UK, pp. $28-44$.

Grant, A.M. and Campbell, E.M. (2007), "Doing good, doing harm, being well and buring out: The interactions of perceived prosocial and antisocial impact in service work", Journal of Occupational and Organizational Psychology, Vol. 80 No. 4, pp. 665-691.

Grant, A.M. and Hofmann, D.A. (2011), “Outsourcing inspiration: The performance effects of ideological messages from leaders and beneficiaries", Organizational Behavior and Human Decision Processes, Vol. 116 No. 2, pp. 173-187.

Guin, K. (2004), “Chronic Teacher Turnover in Urban Elementary Schools Kacey”, Education Policy Analysis Archives, Vol. 12 No. 42, pp. 1-30.

Guramatunhu-Mudiwa, P. and Scherz, S.D. (2013), "Developing psychic income in school administration: The unique role school administrators can play", Educational Management Administration \& Leadership, Vol. 41 No. 3, pp. 303-315. 
Hallinger, P. and Heck, R.H. (2010), “Collaborative Leadership and School Improvement: Understanding the Impact on School Capacity and Student Learning", School Leadership \& Management, Vol. 30 No. 2, pp. 95-110.

Hargreaves, D.H. (1994), "The new professionalism: The synthesis of professional and institutional development", Teaching and Teacher Education, Vol. 10 No. 4, pp. 423-438.

Himeji City Administration. 2017. "Basic Statistics about Schools in Himeji city". Himeji city. Accessed January 14 2018. https://www.city.himeji.lg.jp/toukei/h07/h0717/h0717.html

Hooper, D., Coughlan, J. and Mullen, M. (2008), "Structural equation modelling: Guidelines for determining model fit”, Electronic Journal of Business Research Methods, Vol. 6 No. 1, pp. $53-60$.

Hord, S.M. and Sommers, W.A. (2008), Leading Professional Learning Communities: Voices from Research and Practice, Corwin Press, Thousand Oaks, CA.

Hu, J. and Liden, C.R. (2015), "Making a difference in the teamwork: Linking team prosocial motivation to team processes and effectiveness", Academy of Management Journal, Vol. 58 No. 4, pp. 1102-1127.

Hu, L. and Bentler, P.M. (1999), "Cutoff criteria for fit indixes in covariance structure analysis: Conventional criteria versus new alternatives", Structural Equation Modeling: A Multidisciplinary Journal, Vol. 6 No. 1, pp. 1-55.

Jäppinen, A. and Ciussi, M. (2016), "Indicators of improved learning contexts: a collaborative perspective on educational leadership", International Journal of Leadership in Education, Routledge, Vol. 19 No. 4, pp. 482-504.

Jäppinen, A., Leclerc, M. and Tubin, D. (2015), “Collaborativeness as the core of professional learning communities beyond culture and context: evidence from Canada, Finland, and Israel”, School Effectiveness and School Improvement, Vol. 27 No. 3, pp. 315-332.

Ingersoll, R.M. (2001), "Teacher turnover and teacher shortage", American Educational Research Journal, Vol. 38 No. 3, pp. 499-534. 
Ingersoll, R.M. and Strong, M. (2011), “The impact of induction and mentoring programs for beginning teachers: A critical review of the research", Review of Educational Research, Vol. 81 No. 2, pp. 201-233.

Kaplan, S., Bradley, J., Luchman, J.N. and Haynes, D. (2009), “On the Role of Positive and Negative Affectivity in Job Performance: A Meta-Analytic Investigation", Journal of Applied Psychology, Vol. 94 No. 1, pp. 162-176.

Kinman, G. and Grant, L. (2011), "Exploring Stress Resilience in Trainee Social Workers: The Role of Social and Emotional Competence", British Journal of Social Work, Vol. 41 No. 2, pp. 261-275.

Kline, R. B. (2016). Principles and practice of structural equation modeling (4th ed.). New York, Guilford Press.

Kraft, M.A., Marinell, W.H. and Shen-Wei Yee, D. (2016), "School Organizational Contexts, Teacher Turnover, and Student Achievement: Evidence From Panel Data", American Educational Research Journal, Vol. 53 No. 5, pp. 1411-1449.

Lachman, R. and Diamant, E. (1987), "Withdrawal and restraining factors in teachers' turnover intentions", Journal of Occupational Behavior, Vol. 8 No. 3, pp. 219-232.

Lambert, E. and Hogan, N. (2009), "The importance of job satisfaction and organizational commitment in shaping turnover intent”, Criminal Justice Review Volume, Vol. 34 No. 1, pp. $96-118$.

Ministry of Education Culture Sport Science and Technology Japan. (2016), "STATISTICAL ABSTRACT 2016 edition", available at: http://www.mext.go.jp/b_menu/toukei/002/002b/1356065.htm (accessed 1 January 2018).

Moynihan, D.P. and Pandey, S.K. (2008), "The ties that bind: Social networks, personorganization value fit, and turnover intention", Journal of Public Administration Research and Theory, Vol. 18 No. 2, pp. 205-227.

Muthén, L. and Muthén, B. (2012), Mplus User's Guide, 7th ed., Muthén \& Muthén, Los Angeles: CA.

Noddings, N. (2006), "Educational leaders as caring teachers", School Leadership \& Management, Vol. 26 No. 4, pp. 339-345. 
Podsakoff, P.M., Mackenzie, S.B. and Podsakoff, N.P. (2012), "Sources of method bias in social science research and recommendations on how to control It", Annual Review of Psychology, Vol. 63 No. 1, pp. 539-569.

Preacher, K.J. and Hayes, A.F. (2004), "SPSS and SAS procedures for estimating indirect effects in simple mediation models.", Behavior Research Methods, Instruments, \& Computers : A Journal of the Psychonomic Society, Inc, Vol. 36 No. 4, pp. 717-731.

Rosenblatt, Z., Shapira-Lishchinsky, O. and Shirom, A. (2010), “Absenteeism in Israeli schoolteachers: An organizational ethics perspective", Human Resource Management Review, Vol. 20 No. 3, pp. 247-259.

Ryan, R.M. and Deci, E.L. (2000), "Intrinsic and extrinsic motivations: Classic definitions and new directions", Contemporary Educational Psychology, Vol. 25 No. 1, pp. 54-67.

Science Council of Japan. (2013), "Code of Conduct for Scientists”, available at: http://www.scj.go.jp/ja/info/kohyo/pdf/kohyo-22-s168-1.pdf (accessed 3 November 2017).

Shapira-Lishchinsky, O. (2009), "Israeli male versus female teachers 'intent to leave work", Gender in Management: An International Journal, Vol. 24 No. 7, pp. 543-559.

Shapira-Lishchinsky, O. (2012), “Teachers' withdrawal behaviors: Integrating theory and findings", Journal of Educational Administration, Vol. 50 No. 3, pp. 307-326.

Shapira-Lishchinsky, O. and Rosenblatt, Z. (2009), “Organizational ethics and teachers' intent to leave: An integrative approach", Educational Administration Quarterly, Vol. 45 No. 5, pp. 725-758.

Shapira-Lishchinsky, O. and Rosenblatt, Z. (2010), "School ethical climate and teachers' voluntary absence”, Journal of Educational Administration, Vol. 48 No. 2, pp. 164-181.

Shapira-Lishchinsky, O. and Tsemach, S. (2014), "Psychological empowerment as a mediator between teachers' perceptions of authentic leadership and their withdrawal and citizenship behaviors", Educational Administration Quarterly, Vol. 50 No. 4, pp. 675-712.

Simon, N. and Johnson, S. (2015), "Teacher turnover in high poverty schools: What we know and can do", Teachers College Record, Vol. 117 No. 3, pp. 1-36. 
Slater, L. (2005), "Leadership for collaboration : An affective process", International Journal of Leadership in Education, Vol. 8 No. 4, pp. 321-333.

Smethem, L. (2007), "Retention and intention in teaching careers: Will the new generation stay?", Teachers and Teaching: Theory and Practice, Vol. 13 No. 5, pp. 465-480.

Smith, T.M. and Ingersoll, R.M. (2004), "What are the effects of induction and mentoring on beginning teacher turnover?", American Educational Research Journal, Vol. 41 No. 3, pp. $681-714$.

Somech, A. (2016), "The cost of going the extra mile: The relationship between teachers' organizational citizenship behavior, role stressors, and strain with the buffering effect of job autonomy", Teachers and Teaching: Theory and Practice, Routledge, Vol. 22 No. 4, pp. $426-447$.

Sonnentag, S. and Grant, A.M. (2012), "Doing good at work feels good at home, but not right away: When and why perceived prosocial impact predicts positive affect", Personnel Psychology, Vol. 65 No. 3, pp. 495-530.

Taylor, T., Martin, B., Hutchinson, S. and Jinks, M. (2007), "Examination of leadership practices of principals identified as servant leaders", International Journal of Leadership in Education, Vol. 10 No. 4, pp. 401-419.

Tett, R.P. and Meyer, J.P. (1993), “Job satisfaction, organizational commitment, turnover intention, and turnover: Path analyses based on meta-analytic findings", Personnel Psychology, Vol. 46, pp. 259-293.

Tschannen-Moran, M. (2001), "Collaboration and the need for trust", Journal of Educational Administration, Vol. 39 No. 4, pp. 308-331.

Vagi, R., Pivovarova, M. and Barnard, W.M. (2019), "Keeping our best? A survival analysis examining a measure of preservice teacher quality and teacher attrition", Journal of Teacher Education, advance online publication, Vol. 70 No. 2, pp. 115-127.

Victorino, C., Nylund-Gibson, K. and Conley, S. (2018), "Prosocial behavior in the professoriate", International Journal of Educational Management, Vol. 32 No. 5, pp. 783798. 
You, S. and Conley, S. (2015), "Workplace predictors of secondary school teachers' intention to leave: An exploration of career stages", Educational Management Administration \& Leadership, Vol. 43 No. 4, pp. 561-581. 


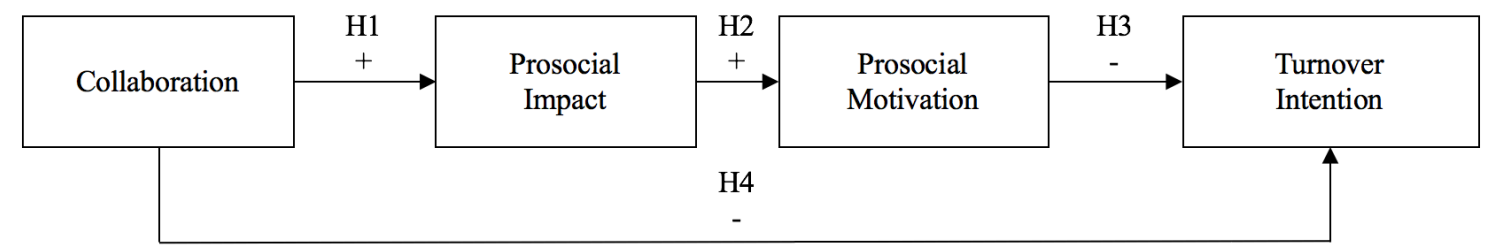

Figure 1. Theoretical Model of the Study based on the model by Grant (2007) 


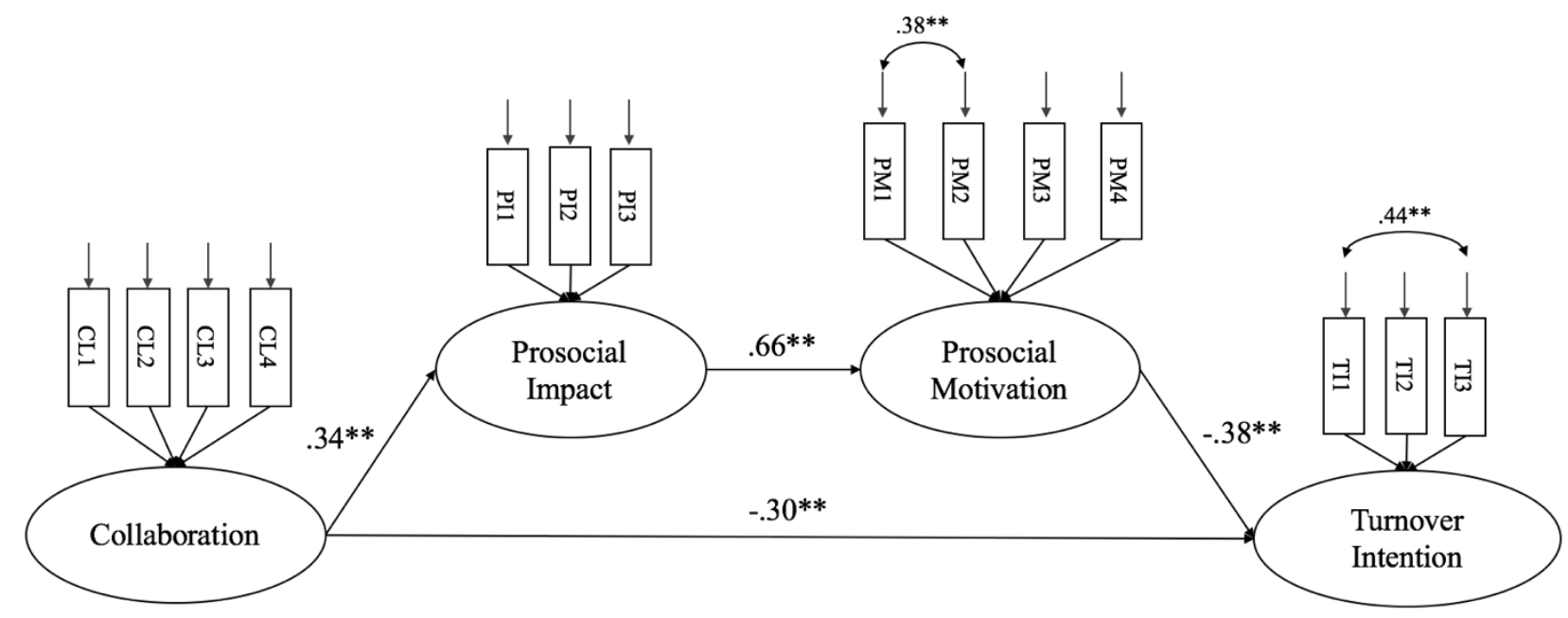

NOTE: $* *$ p value $<0.01, *$ p value $<0.05$

Figure 2. Structural Model Results for the Overall Mediation Model. Standardized estimates are presented. 
Table 1. Pearson Correlations of the Observed Variables $(\mathrm{N}=260)$

\begin{tabular}{|c|c|c|c|c|c|c|c|c|c|c|c|c|c|c|c|c|}
\hline & Mean & $S D$ & 1 & 2 & 3 & 4 & 5 & 6 & 7 & 8 & 9 & 10 & 11 & 12 & 13 & 14 \\
\hline 1. Collaboration 1 & 39.81 & 7.45 & - & $.45^{* * *}$ & $.36^{* * *}$ & $.46^{* * *}$ & $.20^{* *}$ & $.25^{* * *}$ & $.15^{*}$ & $.26^{* * *}$ & $.26^{* * *}$ & $.18^{* *}$ & $.23^{* * *}$ & -.11 & $-.21^{* *}$ & -.11 \\
\hline 2. Collaboration 2 & 33.18 & 9.86 & & - & $.40^{* * *}$ & $.47^{* * *}$ & $.20^{* *}$ & $.28^{* * *}$ & $.27^{* * *}$ & $.16^{* *}$ & $.23^{* * *}$ & .12 & .12 & $-.14^{*}$ & $-.25^{* * *}$ & $-.18^{* *}$ \\
\hline 3. Collaboration 3 & 34.30 & 9.78 & & & - & $.60^{* * *}$ & $.18^{* *}$ & $.30^{* * *}$ & $.21^{* *}$ & $.24^{* * *}$ & $.25^{* * *}$ & $.23^{* * *}$ & $.25^{* * *}$ & $-.13^{*}$ & $-.22^{* *}$ & $-.13^{*}$ \\
\hline 4. Collaboration4 & 37.08 & 8.73 & & & & - & .09 & $.20^{* *}$ & $.14^{*}$ & $.28^{* * *}$ & $.24^{* * *}$ & $.24^{* * *}$ & $.23^{* * *}$ & $-.26^{* * *}$ & $-.18^{* *}$ & $-.17^{* *}$ \\
\hline 5. Prosocial Impact1 & 4.62 & 1.44 & & & & & - & $.80^{* * *}$ & $.70^{* * *}$ & $.40^{* * *}$ & $.41^{* * *}$ & $.58^{* * *}$ & $.50^{* * *}$ & -.10 & $-.25^{* * *}$ & $-.14^{*}$ \\
\hline 6. Prosocial Impacct2 & 4.66 & 1.27 & & & & & & - & $.66^{* * *}$ & $.46^{* * *}$ & $.43^{* * *}$ & $.48^{* * *}$ & $.47^{* * *}$ & -.08 & $-.32^{* * *}$ & $-.16^{* *}$ \\
\hline 7. Prosocial ImpactI3 & 4.71 & 1.25 & & & & & & & - & $.37^{* * *}$ & $.42^{* * *}$ & $.56^{* * *}$ & $.47^{* * *}$ & $-.17^{* *}$ & $-.30^{* * *}$ & $-.25^{* * *}$ \\
\hline 8. Prosocial Motivation1 & 5.00 & 1.35 & & & & & & & & - & $.74^{* * *}$ & $.59^{* * *}$ & $.68^{* * *}$ & $-.17^{* *}$ & $-.32^{* * *}$ & $-.23^{* * *}$ \\
\hline 9. Prosocial Motivation2 & 5.03 & 1.41 & & & & & & & & & - & $.59^{* * *}$ & $.73^{* * *}$ & $-.13^{*}$ & $-.29^{* * *}$ & $-.18^{* *}$ \\
\hline 10. Prosocial Motivation3 & 4.78 & 1.40 & & & & & & & & & & - & $.73^{* * *}$ & $-.14^{*}$ & $-.25^{* * *}$ & $-.24^{* * *}$ \\
\hline 11. Prosocial Motivation4 & 4.97 & 1.37 & & & & & & & & & & & - & $-.15^{*}$ & $-.29^{* * *}$ & $-.20^{* *}$ \\
\hline 12. Turnover Intention 1 & 2.01 & 1.56 & & & & & & & & & & & & - & $.26^{* * *}$ & $.55^{* * *}$ \\
\hline 13. Turnover IntentionI2 & 3.37 & 1.84 & & & & & & & & & & & & & - & $.40^{* * *}$ \\
\hline 14. Turnover IntentionI3 & 2.58 & 1.73 & & & & & & & & & & & & & & - \\
\hline
\end{tabular}

NOTE: $* * * \mathrm{p}<0.001$ (2-tailed), $* * \mathrm{p}<0.01$ (2-tailed), $* \mathrm{p}<0.05$ (2-tailed) 